\title{
Analisis Kesalahan Siswa dan Pemberian Scaffolding Pada Materi Operasi Bilangan Bulat
}

\author{
Linda Asiawati, Badruttamam, Alfin Hidayat, Hasan Basri \\ Pendidikan Matematika, FKIP, Universitas Madura. \\ E-mail: asiawatilinda@gmail.com, badruttaman@unira.ac.id, alfin@unira.ac.id, hasan@unira.ac.id
}

\begin{abstract}
Abstrak
Penelitian ini bertujuan untuk menguraikan bentuk scaffolding yang akan diberikan kepada siswa berdasarkan kesalahannya. Pendekatan yang digunakan adalah deskriptif kualitatif. Penelitian dilakukan di sekolah dasar di Pamekasan dengan 14 siswa. Metode pengumpulan data dimulai dengan meminta peserta didik untuk menyelesaikan soal terkait operasi bilangan bulat khususnya penjumlahan dan pengurangan selanjutnya mengidentifikasi kesalahan melalui lembar jawaban siswa kemudian dilakukan wawancara untuk memastikan pola kesalahan siswa. Hasilnya dari 14 siswa ditemukan 4 jenis kesalahan yang dilakukan diantaranya siswa tidak memahami bilangan negatif; siswa tidak dapat membuat model matematika pada soal cerita dengan baik; siswa kesulitan pada saat ada operasi pengurangan dan tanda negatif pada bilangan yang berurutan; siswa tidak teliti dalam mengerjakan. Adapun scaffolding yang diberikan berdasarkan kesalahan siswa adalah bagi siswa yang tidak memahami bilangan negatif bisa di ilustrasikan dengan menggunakan kartu bermuatan; bagi siswa yang kesulitan dalam memodelkan soal cerita dengan benar, menggunakan ilustrasi dari kehidupan nyata yang sering dihadapi; menggunakan alat peraga kartu bilangan bermuatan atau dengan menggunakan garis bilangan dengan aturan yang telah ditetapkan terlebih dahulu; untuk siswa yang ceroboh, memberikan saran agar selalu mengecek jawaban setelah mengerjakan soal. Berdasarkan hasil pre tes dan post tes terlihat bahwa ada perbaikan hasil nilai siswa setelah memperoleh scaffolding.
\end{abstract}

Kata Kunci: kesalahan; scaffolding; operasi; bilangan bulat.

\begin{abstract}
This study aims to describe the form of scaffolding that will be given to students based on their mistakes. The approach used is descriptive qualitative. The study was conducted in an elementary school in Pamekasan with 14 students. The method of data collection begins by asking students to solve problems related to integer operations, especially addition and subtraction, then identifying errors through student answer sheets and then conducting interviews to ascertain the pattern of student errors. This study resulted in 14 students found four types of mistakes made. This study obtained results from 14 students who found four types of errors. First, the students do not understand negative numbers. Second, students cannot make mathematical models on story problems properly. Third, students had difficulty when there were subtraction operations and negative signs on consecutive numbers. Four students were not careful in their work. Scaffolding is given by illustrating charged cards. Also, students who have difficulty in correctly modeling story problems are given illustrations from real life that they often face. The use of props containing numbered cards or by using the number line is done by the rules that have been set. Careless students are advised to always check answers after working on the problems. Based on the results of the pre-test and post-test, it appears that there is an improvement in the results of student grades after obtaining scaffolding.
\end{abstract}

Keyword : error analisis; Scaffolding; Integer Operation 


\section{A. INTRODUCTION}

Matematika adalah ilmu yang memiliki keterkaitan dengan bidang ilmu lainnya seperti kimia, fisika, ekonomi, geografi dan Biologi. Hal itulah yang menyebabkan matematika dijuluki sebagai Ibu dari ilmu pengetahuan yang lain, oleh karenanya sangat penting bagi siswa untuk memahami matematika dalam rangka menunjang pengetahuan pada bidang ilmu lainnya. Objek-objek dalam pembelajaran matematika terdiri dari fakta, konsep, prinsip dan keterampilan. ${ }^{1}$

Fakta adalah konvensi (kesepakatan) dalam matematika seperti lambang, notasi, ataupun aturan. Konsep adalah suatu ide abstrak yang memungkinkan seseorang untuk mengklasifikasi suatu objek dan menerangkan apakah objek tersebut merupakan contoh atau bukan contoh dari ide abstrak tersebut. Prinsip adalah yang memuat hubungan antara dua konsep atau lebih, sedangkan keterampilan terkait dengan kemampuan siswa dalam melakukan prosedur.

Operasi penjumlahan dan pengurangan pada bilangan bulat merupakan dasar dari beberapa materi yang lain, oleh karenanya kemampuan siswa dalam melakukan operasi penjumlahan dan pengurangan bilangan bulat sangat dibutuhkan. Terkait pembelajaran operasi bilangan bulat, berdasarkan observasi yang dilakukan di beberapa sekolah dasar di Pamekasan, banyak guru yang mengajarkan siswa

\footnotetext{
${ }^{1}$ Kusrini, Mayon, and Susanah Wijayanti, Strategi Pembelajaran Matematika.
}

terkait operasi bilangan bulat dengan menggunakan bantuan garis bilangan dengan cara menggambar garis bilangan di papan tulis, tanpa menghadirkan objek tersebut secara langsung.

Melalui interview yang dilakukan dengan beberapa guru, ditemukan fakta bahwa masih banyak siswa yang kesulitan dalam melakukan operasi penjumlahan dan pengurangan bilangan bulat. Selama ini masih banyak guru yang menyampaikan operasi penjumlahan dan pengurangan bilangan bulat dengan menggunakan garis bilangan namun belum konsisten, misalnya pada saat melakukan operasi 2-(-3) guru belum mampu mengaplikasikan makna "-" yang pertama dengan "-" yang menempel pada bilangan 3 di garis bilangan dan menganggap $-(-\ldots)$ sebagai perkalian negatif dengan negatif.

Penelitian sebelumnya terkait bilangan bulat telah dilakukan oleh beberapa peneliti diantaranya Badriyah, Priyoko, dan Ugi \& Darwis. ${ }^{2}$ Ketiga peneliti tersebut melakukan penelitian terkait operasi hitung pada bilangan bulat. Dari ketiga penelitian tersebut hanya Ugi \& Darwis yang memberikan alternatif pemecahan terkait kesalahan yang dilakukan oleh siswa dalam

\footnotetext{
2 Badriyah, As'ari, and Susanto, "Profil Kesalahan Siswa SMP Dalam Menyelesaikan Operasi Hitung Bilangan Bulat"; Ugi, "ANALISIS KESALAHAN SISWA PADA OPERASI HITUNG CAMPURAN BILANGAN BULAT DAN ALTERNATIF PEMECAHANNYA"; Priyoko, "Analisis Kesalahan Siswa Menurut Newman Dalam Menyelesaiakn Soal Cerita Materi Operasi Hitung Pengurangan Bilangan Bulat Kelas VII B SMP Pangudi Luhur Salatiga.”
} 
melakukan operasi hitung campuran bilangan bulat. ${ }^{3}$

Dalam dunia pendidikan tentu saja analisis siswa dalam melakukan kesalahan sangatlah penting, karena hal itu merupakan salah satu modal bagi guru untuk melakukan evaluasi terkait metode pembelajaran yang dilakukan serta bantuan seperti apa yang tepat untuk mengatasi kesalahan yang dilakukan oleh siswa. Namun demikian harus diimbangi dengan pemberian bantuan (Scaffolding) sangat diperlukan agar siswa tidak melakukan kesalahan yang serupa atau mengalami misconception. ${ }^{4}$ Berdasarkan uraian di atas penulis tertarik untuk melakukan penelitian terkait "analisis kesalahan siswa dan scaffolding siswa dalam menyelesaikan operasi penjumlahan dan pengurangan bilangan bulat pada siswa sekolah dasar".

\section{B. METODE PENELITIAN}

Jenis penelitian adalah penelitian deskriptif kualitatif. Penelitian ini bertujuan untuk menganalisis kesalahan siswa dalam melakukan operasi penjumlahan dan pengurangan bilangan bulat dan scaffolding yang diberikan untuk mengurangi bahkan menghilangkan kesalahan serupa pada saat mengerjakan operasi penjumlahan dan pengurangan bilangan bulat.

Subjek penelitian adalah siswa SD yang telah mempelajari materi penjumlahan dan pengurangan bilangan bulat di salah satu Sekolah Dasar di

\footnotetext{
${ }^{3}$ Ugi, “ANALISIS KESALAHAN SISWA PADA OPERASI HITUNG CAMPURAN BILANGAN BULAT DAN ALTERNATIF PEMECAHANNYA." ${ }^{4}$ Anghileri, "Scaffolding Practices That Enhance Mathematics Learning."
}

Kabupaten Pamekasan. Subjek dalam penelitian ini sebanyak 14 siswa SD. Adapun teknik pengumpulan dilakukan melalui observasi, wawancara dan tes. Tes terdiri dari dua jenis, yaitu pre tes dan pos tes yang terdiri dari 10 soal. Soal tersebut telah di validasi sebelumnya oleh 1 guru dan 1 orang dosen. Soal ini merupakan soal diagnotis yang memang sengaja dibuat guna mengidentifikasi kesalahan siswa dalam melakukan operasi bilangan bulat.

\section{HASIL DAN PEMBAHASAN}

Berdasarkan hasil pre tes diperoleh informasi bahwa dari 15 siswa hanya 1 orang yang tidak mengikuti pre tes. Berdasarkan hasil penilaian pre tes diperoleh 3 orang (21\%) siswa yang memiliki nilai lebih dari atau sama dengan 70 (KKM di sekolah tersebut) sedangkan sisanya sebanyak 11 orang (79\%) nilainya kurang dari 70. Terlihat bahwa masih banyak siswa yang mengalami kesulitan dalam mengerjakan soal terkait operasi penjumlahan dan pengurangan bilangan bulat. Berdasarkan hasil pre tes dan wawancara yang dilakukan untuk memperkuat penemuan terkait pola yang kesalahan yang dilakukan oleh siswa diperoleh pengelompokan kesalahan siswa pada materi operasi penjumlahan dan pengurangan bilangan bulat sebagai berikut:

Berdasarkan hasil pre tes dan wawancara diidentifikasi kesalahan siswa dalam 4 kategori kesalahan, selanjutnya akan dipaparkan bagaimana bentuk kesalahan dan scaffolding yang diberikan kepada siswa. Untuk lebih jelasnya, identifikasi 
kesalahan sekaligus scaffolding yang akan diberikan kepada siswa akan dipaparkan lebih rinci sebagai berikut:

A. Kesalahan siswa dalam memahami

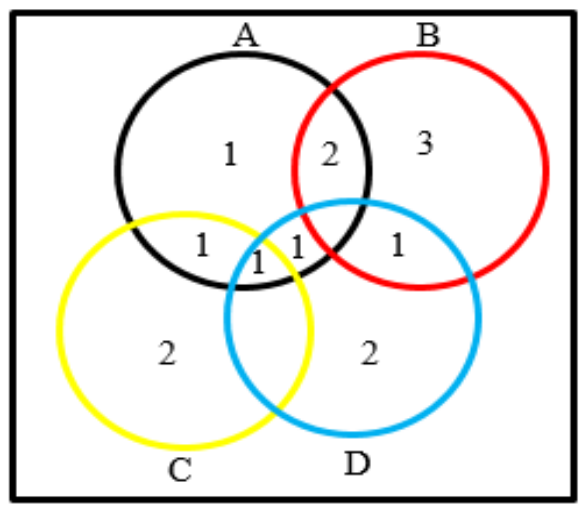

Gambar 1 Klasifikasi kesalahan siswa

Keterangan:

A Kesalahan dalam memahami simbol negatif.

B Siswa tidak dapat membuat model matematika dengan benar

C Siswa kesulitan pada saat ada dua tanda pada soal

D Siswa ceroboh/tidak teliti

simbol negatif, terdapat 6 siswa yang melakukan kesalahan karena tidak memahami simbol negatif. Berikut ini contoh kesalahan siswa yang terjadi karena tidak mampu memahami bilangan negatif dengan baik.

$$
\begin{aligned}
& \text { 3. } 9-(-2)=\ldots \\
& \text { 4. }-11+(-12)=\ldots
\end{aligned}
$$

Gambar 2 Kesalahan Siswa Tidak Memahami Bilangan Negatif
Berdasarkan hasil wawancara dengan siswa yang melakukan kesalahan diperoleh informasi bahwa siswa menganggap -2 sama dengan 2 sehingga pada saat mengerjakan soal 9 - (-2) siswa menggapnya sebagai 9 2 yang hasilnya adalah 7 . Kesalahan ini terjadi karena siswa tidak memahami terkait bilangan bulat negatif. Scaffolding yang diberikan adalah menghadirkan secara langsung objek bilangan negatif dan positif dengan menggunakan kartu bilangan. Berikut ilustrasi yang diberikan kepada siswa agar memudahkan mereka dalam memahami konsep bilangan bulat negatif:

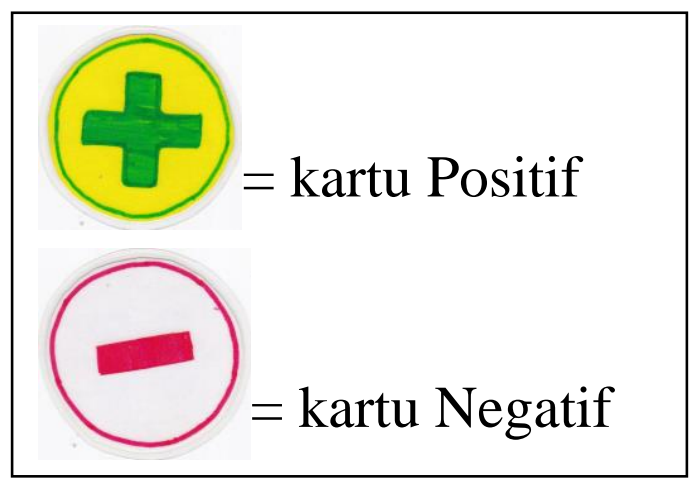

Gambar 3 Kartu bilangan positif dan negatif 
Berikut pengilustrasiannya:

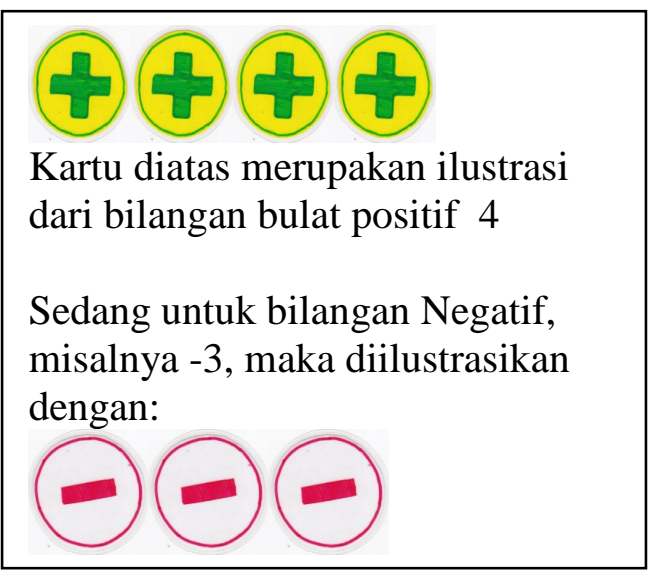

Gambar 4 ilustrasi penggunaan media kartu bilangan

Setelah siswa memperoleh scaffolding selanjutnya, guru memberikan beberapa soal yang mirip dengan soal pada saat pre tes untuk melihat perkembangan siswa setelah memperoleh scaffolding.

B. Siswa tidak dapat membuat model matematika dengan benar. Dua dari sepuluh soal pre tes memang dirancang oleh peneliti untuk mengidentifikasi kesalahan siswa dalam membuat model matematika dari soal cerita. Berikut ini contoh kesalahan siswa yang terjadi karena tidak dapat membuat model matematika dengan baik.

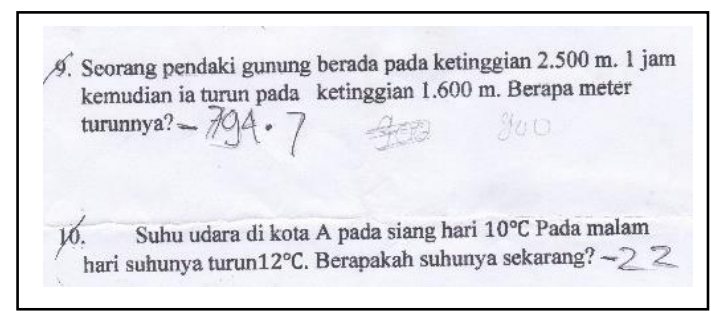

Gambar 5 Kesalahan Siswa dalam memahami soal cerita
Berdasarkan hasil wawancara dengan siswa yang melakukan kesalahan diperoleh informasi bahwa siswa kesulitan dalam memahami kalimat dalam soal. Hal ini sejalan dengan penelitian yang dilakukan oleh Aini yang menyatakan bahwa banyak siswa mengalami kesulitan dalam memahami arti kalimat-kalimat dalam soal cerita. ${ }^{5}$ Scaffolding yang diberikan adalah dengan membiasakan siswa mendengarkan istilah-istilah dalam kehidupan sehari-hari yang erat kaitannya dengan operasi pada

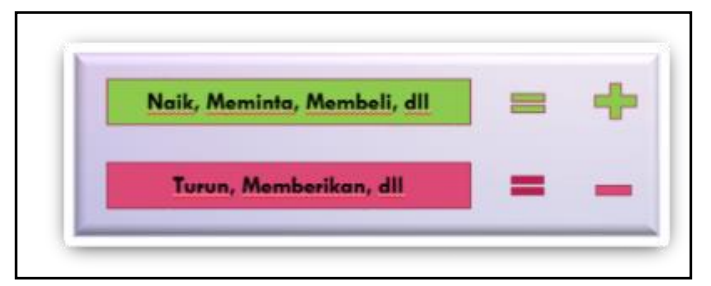

matematika.

Gambar 6 ilustrasi penggunaan media kartu bilangan

Misalnya membeli, diberi, jumlahkan, istilah ini dalam matematika merepresentasikan operasi penjumlahan a+b. Sedangakan menjual, memberikan dan kurangkan, istilah ini dalam matematika merepresentasikan operasi pengurangan a-b. Dengan membiasakan siswa untuk memahami korelasi antara istilah-istilah yang diberikan dengan operasi matematika diharapkan siswa akan mampu memodelkan suatu soal cerita dengan baik. Setelah siswa memperoleh

\footnotetext{
${ }^{5}$ Aini, Jannah, and Masruroh, "Identifikasi Kesalahan Siswa Dalam Menyelesaikan Masalah Trigonometri."
} 
scaffolding selanjutnya, guru memberikan beberapa soal yang mirip dengan soal pada saat pre tes untuk melihat perkembangan siswa setelah memperoleh scaffolding.

C. Siswa kesulitan pada saat ada dua tanda pada soal. Tiga dari sepuluh soal pre tes memang dirancang oleh peneliti untuk mengidentifikasi kesalahan siswa dalam memahami perubahan tanda yang terjadi apabila operasi pengurangan diikuti oleh bilangan negatif. Berikut ini contoh kesalahan yang dilakukan oleh siswa:

$$
\text { 7. } 40-(-45)-20=(-25)
$$

Gambar 7 kesulitan siswa saat ada dua tanda pada soal

Berdasarkan hasil wawancara terkait kesalahan soal diatas terhadap siswa yang melakukan kesalahan adalah siswa memang belum memahami jika ada tanda operasi dan tanda negative pada bilangan bulat bertemu, sehingga ia menganggapnya tanda yang ada pada bilangan tidak berpengaruh (tidak dianggap). Hal senada juga disampaikan oleh Ugi dkk (2016) bahwa siswa sering melakukan kesalahan dalam menyelesaikan soalsoal operasi hitung bilangan bulat, terutama kesalahan dalam urutan pengerjaan operasi hitung serta membedakan $40+45$ dan $40-45$ sebagai operasi hitung dengan tanda yang terkadang bersamaan seperti -5 $(-7)$.
Scaffolding yang diberikan adalah dengan alat bantu peraga dalam hal ini adalah kartu bermuatan. Penggunaan media dalam pembelajaran dapat meningkatkan hasil belajar siswa. ${ }^{6}$ Dengan menggunakan media kartu bermuatan siswa dibimbing untuk menemukan sendiri perubahan tanda yang terjadi apabila ada operasi pengurangan yang diikuti oleh bilangan negatif, maupun operasi penjumlahan yang diikuti oleh bilangan negatif. Berikut ini akan dipaparkan terkait aturan dan tata cara penggunaan kartu bermuatan.

1. Kita buat kesepakatan terlebih dahulu bahwa kartu bermuatan negatif digunakan untuk bilangan negatif, dan kartu bermuatan positif digunakan untuk bilangan bulat positif.

2. Definisikan bilangan nol sebagai pasangan kartu bilangan positif dan kartu bilangan bulat negatif, artinya apabila ada kartu yang berpasangan maka itu sama dengan bilangan nol.

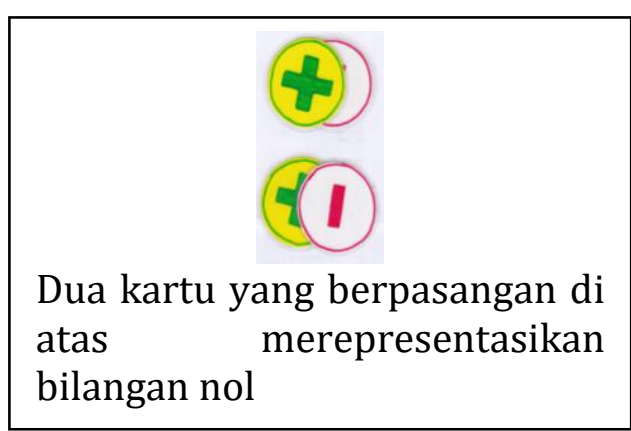

\footnotetext{
${ }^{6}$ Indahwati and Basri, "PENGARUH PENGGUNAAN FACEBOOK SEBAGAI MEDIA PEMBELAJARAN TERHADAP HASIL BELAJAR MAHASISWA."
} 
3. Definisikan suatu bilangan bulat positif sebagai banyaknya kartu kuning yang tidak berpasangan, dan definisikan suatu bilangan negatif sebagai banyaknya kartu putih yang tidak berpasangan.

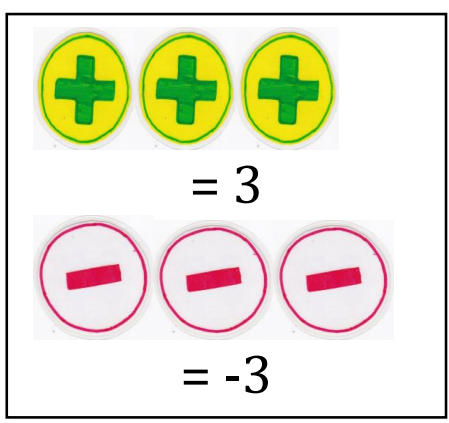

4. Untuk operasi penjumlahan maka dilakukan dengan cara menambahkan kartu bilangan sesuai dengan bilangan yang akan ditambahkan

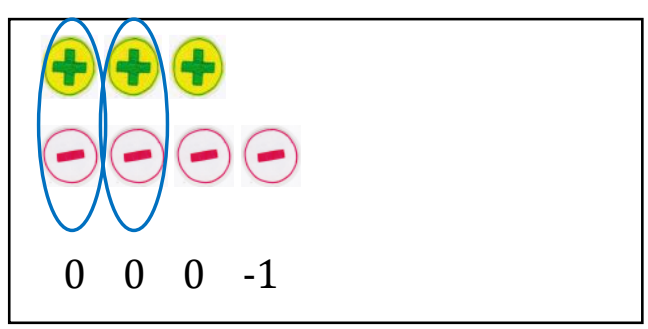

5. Sedangkan pada operasi pengurangan maka cara yang dilakukan adalah dengan mengambil kartu bilangan sesuai dengan pengurang dari bilangan tersebut

Setelah siswa memperoleh scaffolding selanjutnya, guru memberikan beberapa soal yang mirip dengan soal yang diberikan saat pre tes sebagai berikut:
Selanjutnya siswa diminta untuk menyimpulkan sendiri perubahan operasi yang terjadi sebagai berikut:

Untuk mengetahui perkembangan siswa dalam menyerap scaffolding yang diberikan, peneliti memberikan kembali beberapa soal dan meminta siswa untuk mengerjakan soal tersebut tanpa menggunakan kartu bermuatan.
1. $-2+3=1$
2. $-6+8=2$
3. $7+3=10$

D. Siswa ceroboh/tidak teliti, terdapat 5 siswa yang melakukan kesalahan karena ceroboh/tidak teliti Berikut ini contoh kesalahan siswa yang terjadi

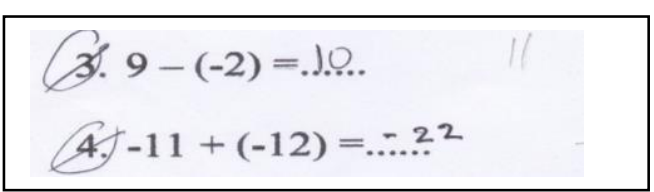

karena ceroboh/tidak teliti.

Berdasarkan wawancara kepada siswa yang memiliki kesalahan jawaban soal diatas ternyata ia hanya salah dalam proses menjumlahkan saja, karena kurang hati-hati dan teliti. Dari pekerjaan siswa di atas terlihat siswa ceroboh dalam mengurangi dua bilangan bulat, hal ini juga didukung dari wawancara yang dilakukan peneliti kepada siswa. Kesalahan siswa karena kurang teliti dan terburu-buru dalam menghitung juga 
ditemukan dalam penelitian yang dilakukan oleh Muammanah. ${ }^{7}$

Scaffolding yang diberikan adalah dengan memberikan nasehat kepada siswa agar tidak terburu-buru dalam mengerjakan soal serta selalu memeriksa kembali jawabannya agar tidak terjadi kesalahan yang terjadi karena ceroboh atau tidak hati-hati.

\section{PENUTUP}

\section{Simpulan}

Berdasarkan penelitian yang telah dilakukan diperoleh bahwa kesalahan yang dilakukan siswa dalam melakukan operasi penjumlahan dan pengurangan adalah Kesalahan dalam memahami simbol negatif; Siswa tidak dapat membuat model matematika dengan benar; Siswa kesulitan pada saat ada operasi dan tanda pada negatif pada bilangan yang berurutan; Siswa ceroboh/tidak teliti.

Scaffolding yang digunakan untuk mengatasi kesalahan-kesalahan yang dilakukan oleh siswa diantaranya menghadirkan secara langsung objek bilangan negatif dan positif secara langsung dengan menggunakan kartu bilangan; scaffolding yang diberikan adalah dengan membiasakan siswa mendengarkan istilah-istilah dalam kehidupan sehari-hari yang erat kaitannya dengan operasi pada matematika; Scaffolding yang diberikan adalah dengan alat bantu peraga dalam hal ini adalah kartu bermuatan. Dengan

\footnotetext{
${ }^{7}$ Muammanah, Subaidi, and Supardi, “Analisis Kesalahan Siswa MA Al-Falah Branta Tinggi Dalam Menyelesaikan Soal UN Matematika Pokok Bahasan Statistika Kelas XI."
}

menggunakan kartu bermuatan siswa dibimbing untuk menemukan sendiri perubahan tanda yang terjadi apabila ada operasi pengurangan yang diikuti oleh bilangan negatif, maupun operasi penjumlahan yang diikuti oleh bilangan negatif dan dengan memberikan nasehat kepada siswa agar tidak terburu-buru dalam mengerjakan soal serta selalu memeriksa kembali jawabannya agar tidak terjadi kesalahan yang terjadi karena ceroboh atau tidak hati-hati.

\section{Saran}

Penelitian ini masih memiliki beberapa kekurangan diantaranya, topik yang disajikan sangat sempit karena hanya membahas terkait operasi penjumlahan dan pengurangan saja. Diharapkan peneliti yang lain bisa melanjutkan penelitian terkait bilangan bulat pada topik yang berbeda, misalnya pada perkalian dan pembagian bilangan bulat atau materi yang lain.

\section{E. DAFTAR PUSTAKA}

Aini, Septi Dariyatul, Ukhti Raudhatul Jannah, and Ririn Masruroh. "Identifikasi Kesalahan Siswa Dalam Menyelesaikan Masalah Trigonometri." Jurnal SIGMA 3, no. 1 (2017): 17-25.

https://doi.org/10.0324/sigma.v3i1. 337.

Anghileri, Julia. “Scaffolding Practices

That Enhance Mathematics

Learning." Journal of Mathematics

Teacher Education 9, no. 1 (February 2006): 33-52.

https://doi.org/10.1007/s10857006-9005-9.

Badriyah, Lailatul, A. R As'ari, and H 
Susanto. "Profil Kesalahan Siswa SMP

Dalam Menyelesaikan Operasi

Hitung Bilangan Bulat." In Seminar

Matematika Dan Pembelajarannya.

Malang: Universitas Negeri Malang, 2016.

Indahwati, Rohmah, and Hasan Basri.

"PENGARUH PENGGUNAAN

FACEBOOK SEBAGAI MEDIA

PEMBELAJARAN TERHADAP HASIL

BELAJAR MAHASISWA." JURNAL

SILOGISME : Kajian Ilmu Matematika

Dan Pembelajarannya 2, no. 2

(December 30, 2017): 74-83.

https://doi.org/10.24269/JS.V2I2.78

7.

Kusrini, Kusrini, J.T Mayon, and P.

Susanah Wijayanti. Strategi

Pembelajaran Matematika.

Tangerang Selatan: Universitas

Terbuka, 2014.

Muammanah, , Agus Subaidi, and Lili

Supardi. "Analisis Kesalahan Siswa

MA Al-Falah Branta Tinggi Dalam

Menyelesaikan Soal UN Matematika

Pokok Bahasan Statistika Kelas XI."

Jurnal Pendidikan Matematika Dan

Integrasinya 2, no. 1 (November 30,

2018): 56-64.

Priyoko, Aditya. "Analisis Kesalahan

Siswa Menurut Newman Dalam

Menyelesaiakn Soal Cerita Materi

Operasi Hitung Pengurangan

Bilangan Bulat Kelas VII B SMP

Pangudi Luhur Salatiga." UKSW, 2010.

Ugi, La Eru. "ANALISIS KESALAHAN

SISWA PADA OPERASI HITUNG

CAMPURAN BILANGAN BULAT DAN

ALTERNATIF PEMECAHANNYA."

Jurnal Daya Matematis 4, no. 1 (July
30, 2016): 34 .

https://doi.org/10.26858/jds.v4i1.2 450. 
216| ibriez $\mid \begin{aligned} & \text { Junnal Kependidikan Dasa } \\ & \text { Islam Berbasis Sains }\end{aligned}$ Vol 3 No 2 Tahun 2018 